\title{
Shape-Controlled Narrow-Gap SnTe Nanostructures: From Nanocubes to Nanorods and Nanowires
}

\author{
Shaojun Guo ${ }^{1 *}$, Andrew F. Fidler ${ }^{1}$, Kai $\mathrm{He}^{2}$, Dong $\mathrm{Su}^{2}$, Gen $\mathrm{Chen}^{3}$, Qianglu Lin ${ }^{1}$, Jeffrey M. Pietryga*1 \\ and Victor I. Klimov ${ }^{1 *}$ \\ ${ }^{1}$ Center for Advanced Solar Photophysics, Chemistry Division, Los Alamos National Laboratory, Los \\ Alamos, New Mexico 87545, United States. \\ ${ }^{2}$ Center for Functional Nanomaterials, Brookhaven National Laboratory, Upton, New York 11973, USA \\ ${ }^{3}$ Department of Chemical Engineering, New Mexico State University, Las Cruces, New Mexico 88003, \\ United States
}

\section{Experimental Details}

Chemicals and Materials. Oleic acid (OA, 90\%), oleylamine (OAm, 80-90\%), tellurium (99.999\%), tetrachloroethylene (TCE, spectrophotometric grade, $\geq 99 \%$ ), trioctylamine (98\%), trioctylphosphine (TOP, 97\%), diisobutylphosphine (DIP, 99\%), hexane (99.99\%), toluene (99.99\%), chloroform (99.99\%), isopropanol (99.99\%) and acetonitrile $(99.8 \%)$ were purchased from Aldrich. Tin(II) iodide (99\%) was obtained from Alfa Aesar. All chemicals were used as received without any further purification. All syntheses were carried out using standard air-free Schlenk-line and glovebox techniques.

Characterization. The size, shape and composition of SnTe nanocrystals were characterized by transmission electron microscopy (TEM, JEOL JEM 2010) operating at an accelerating voltage of $200 \mathrm{kV}$, and equipped with an energy-dispersive X-ray (EDX) spectrometer (Bruker Quantax). Samples for TEM characterization were prepared by placing several drops of a diluted nanocrystal solution onto a carbon-coated copper grid. Scanning transmission electron microscopy (STEM) analyses were carried out using a Hitachi HD2700C $(200 \mathrm{kV})$ with a probe aberration-corrector, in the Center for Functional Nanomaterials at Brookhaven National Lab. The 2D electron energy-loss spectroscopy (EELS) mapping was collected using a high resolution Gatan-Enfina ER with a probe size of $1.3 \AA$. A power law function was used for EELS background subtraction. EDX spectra were collected at several locations for each TEM sample. Fourier transform infrared (FT-IR) spectroscopy was taken using a BOMEM DA8 FT-IR spectrometer operating from 8000 to $1000 \mathrm{~cm}^{-1}$. Wide-angle powder XRD patterns of SnTe nanocrystals were recorded on a Rigaku MiniFlex II X-ray powder diffractometer (XRD) with $\mathrm{Cu} \mathrm{K} \alpha$ radiation $(\lambda=1.5418 \AA)$.

Synthesis of SnTe Nanocubes. The TOPTe solution (2 M) was prepared in a glovebox by dissolving tellurium shot in TOP by stirring at room temperature for one week. In a typical synthesis of SnTe nanocubes, $1 \mathrm{mmol} \mathrm{SnI}_{2}, 5 \mathrm{~mL}$ of OAm and $5 \mathrm{~mL}$ TOA were mixed in a 100 
$\mathrm{mL}$ three-neck flask, then degassed and dried under vacuum for $30 \mathrm{~min}$ at $90^{\circ} \mathrm{C}$. The clear solution was then heated to $160{ }^{\circ} \mathrm{C}$, followed by the rapid injection of $0.5 \mathrm{~mL}$ of $2 \mathrm{M}$ TOPTe solution with a syringe, and heated to $240{ }^{\circ} \mathrm{C}$ for $10-20$ mins to get SnTe nanocubes. A hexane/toluene mixture (1:1) was added to the crude solution, and the nanocubes were precipitated by addition of acetonitrile, and isolated by centrifuging. Finally, the nanocubes were dispersed in nonpolar solvents to form stable concentrated colloidal solutions.

Synthesis of SnTe Nanorods. In a typical synthesis of SnTe NCs, $1 \mathrm{mmol} \mathrm{SnI}_{2}, 5 \mathrm{~mL}$ of OAm and $5 \mathrm{~mL}$ TOA were mixed in a $100 \mathrm{~mL}$ three-neck flask, then degassed and dried under vacuum for $30 \mathrm{~min}$ at $100{ }^{\circ} \mathrm{C}$. The clear solution was then cooled down to $40{ }^{\circ} \mathrm{C}$, followed by the rapid injection of $0.5 \mathrm{~mL}$ of $2 \mathrm{M}$ TOPTe solution containing $0.05-0.1 \%$ DIP with a syringe, and then heated to $180{ }^{\circ} \mathrm{C}$ for different times to get SnTe nanorods with different aspect ratio. The purification process for $\mathrm{SnTe}$ nanorods was the same as that of nanocubes.

\section{Figures}

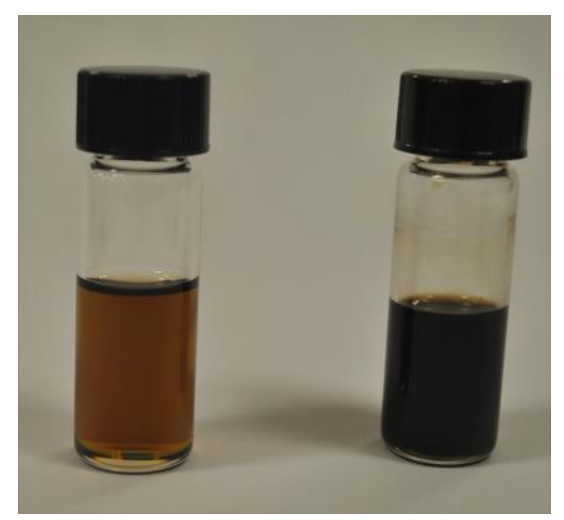

Figure S1. Photograph of SnTe nanocubes dispersed in a mixture of hexane and toluene. Left: low concentration; Right: high concentration. 
$\mathbf{a}$

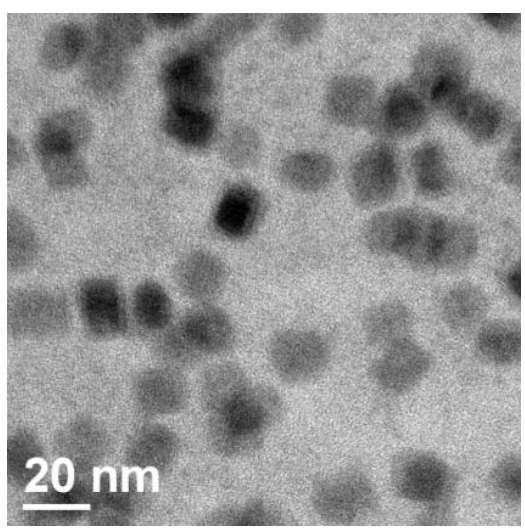

c

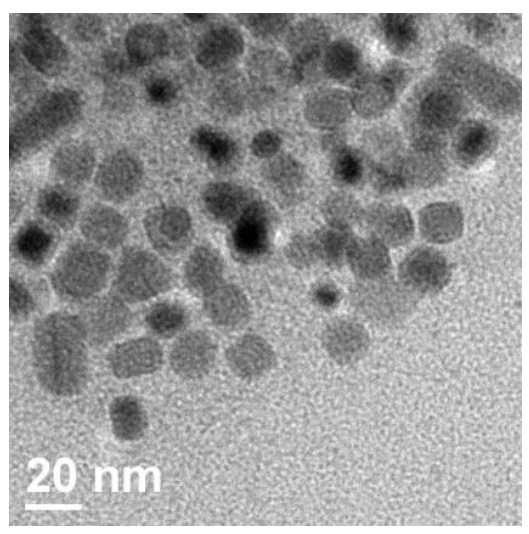

$\mathbf{e}$

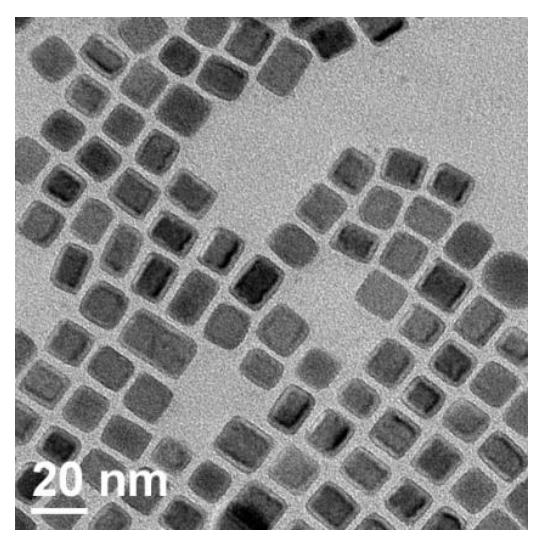

b

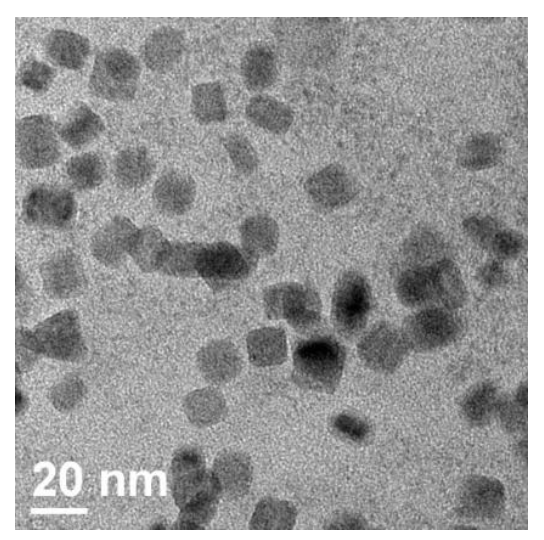

d

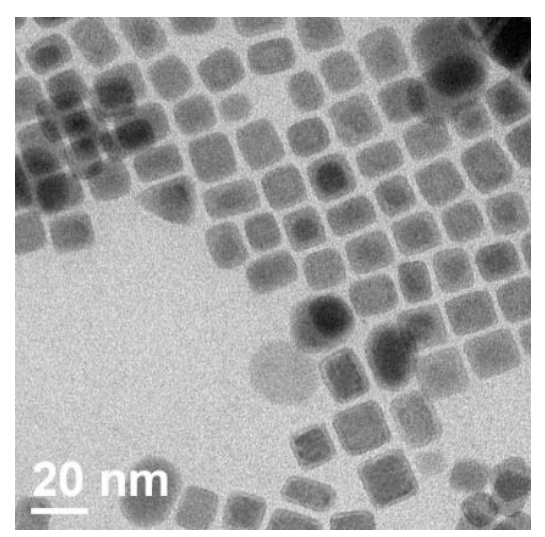

f

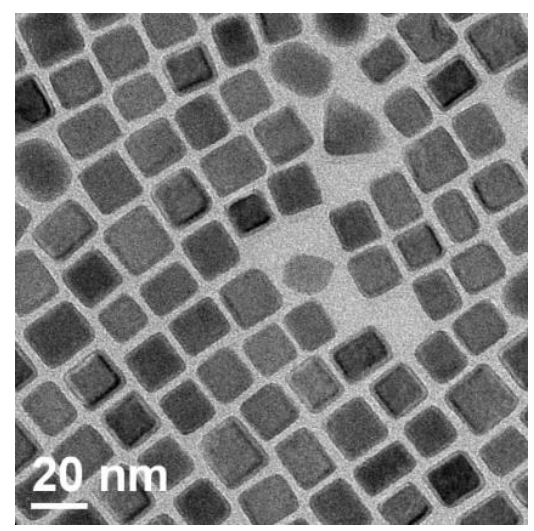

Figure S2. Time-dependent TEM images of SnTe NCs prepared at different temperatures. (a) $170^{\circ} \mathrm{C}$; (b) $180{ }^{\circ} \mathrm{C}$; (c) $190{ }^{\circ} \mathrm{C}$; (d) $200{ }^{\circ} \mathrm{C}$; (e) $215^{\circ} \mathrm{C}$; (f) $240{ }^{\circ} \mathrm{C}$. 
a

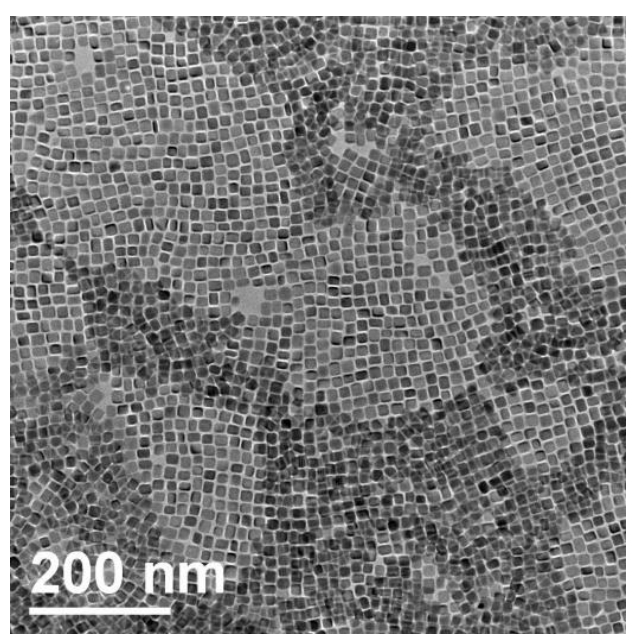

c

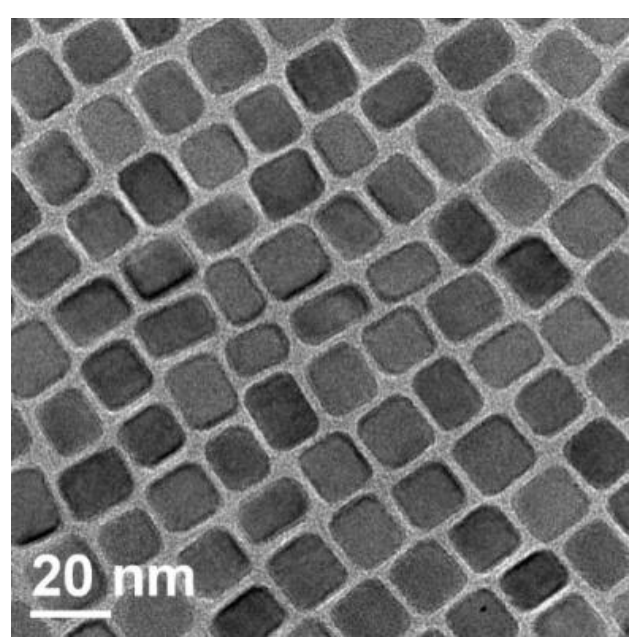

b

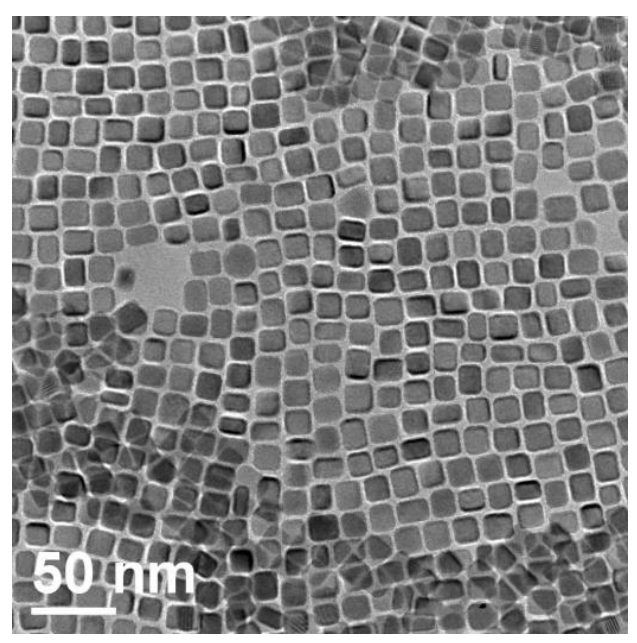

d

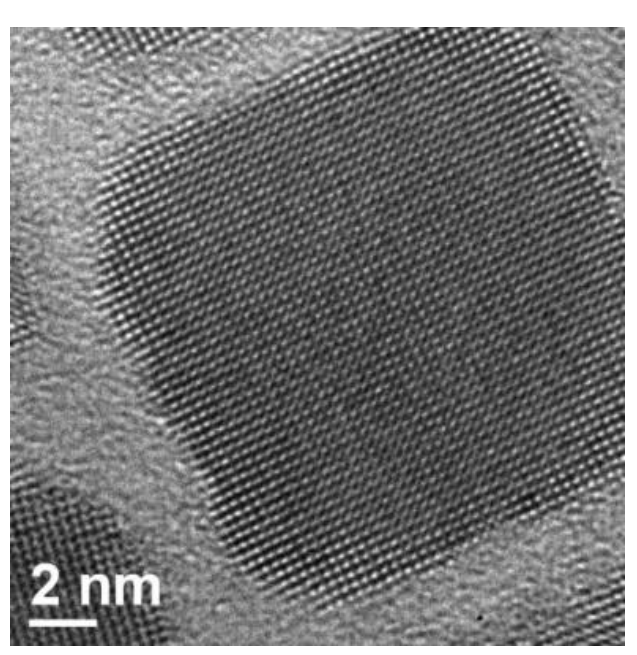

Figure S3. TEM images of SnTe nanocubes prepared at $240{ }^{\circ} \mathrm{C}$ for $20 \mathrm{~min}$. 


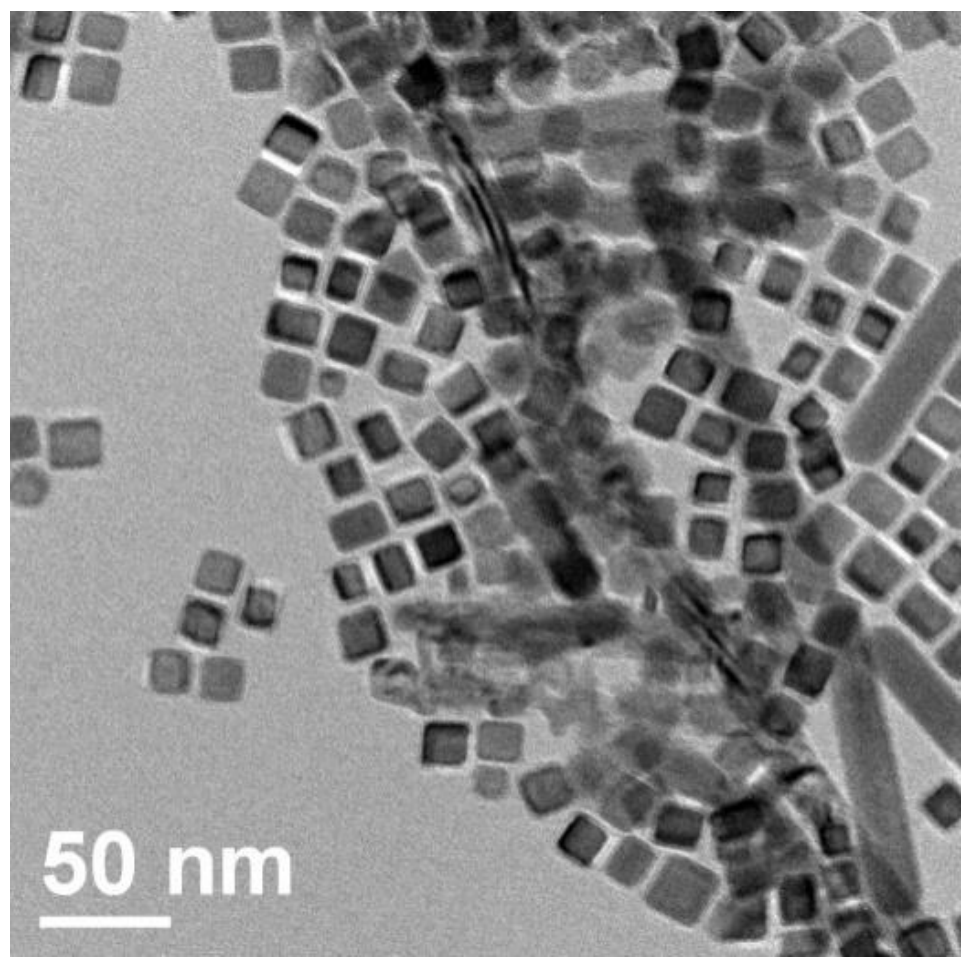

Figure S4. TEM images of SnTe NCs prepared at $240{ }^{\circ} \mathrm{C}$ for $30 \mathrm{~min}$.

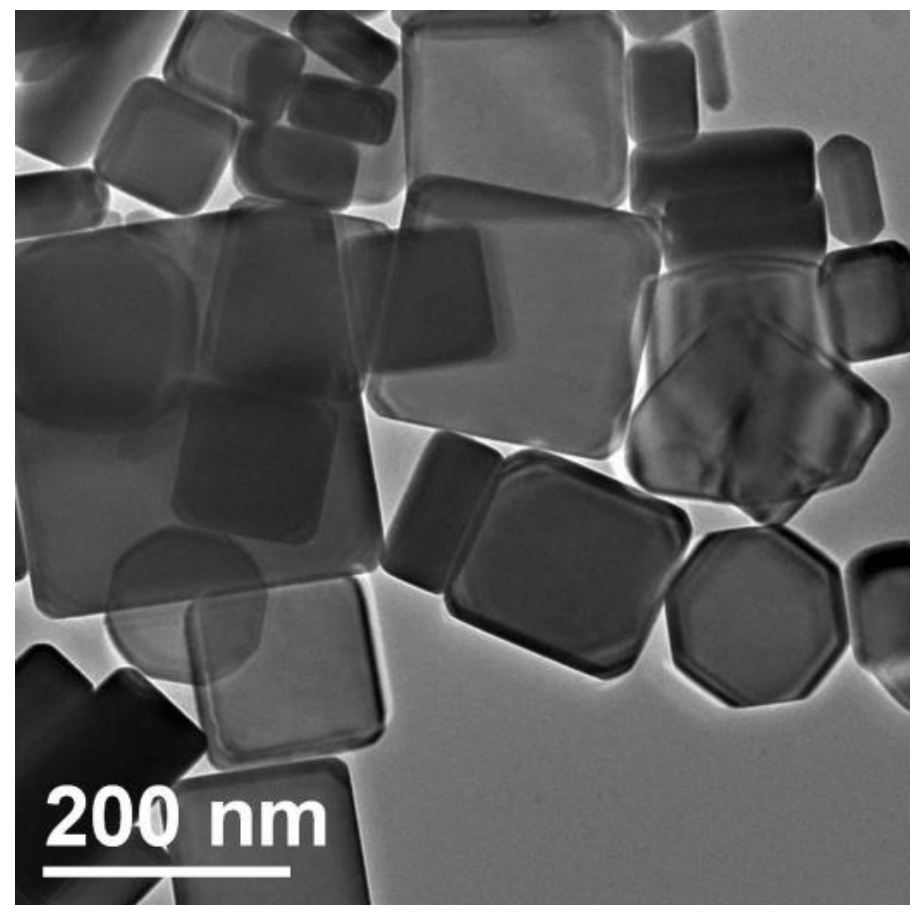

Figure S5. TEM images of SnTe NCs prepared at $240{ }^{\circ} \mathrm{C}$ for $18 \mathrm{~h}$. 

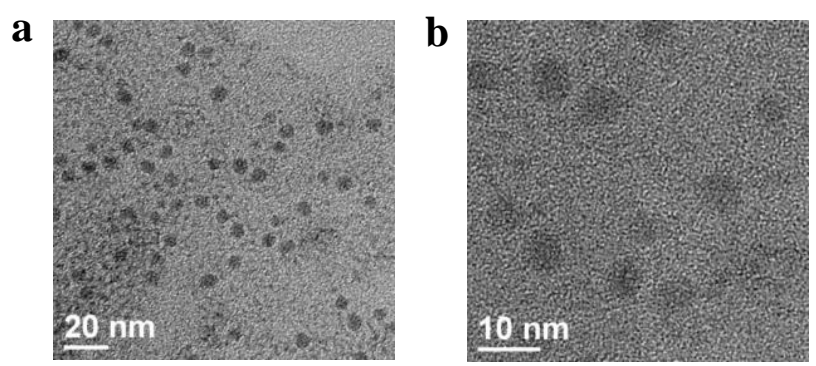

c
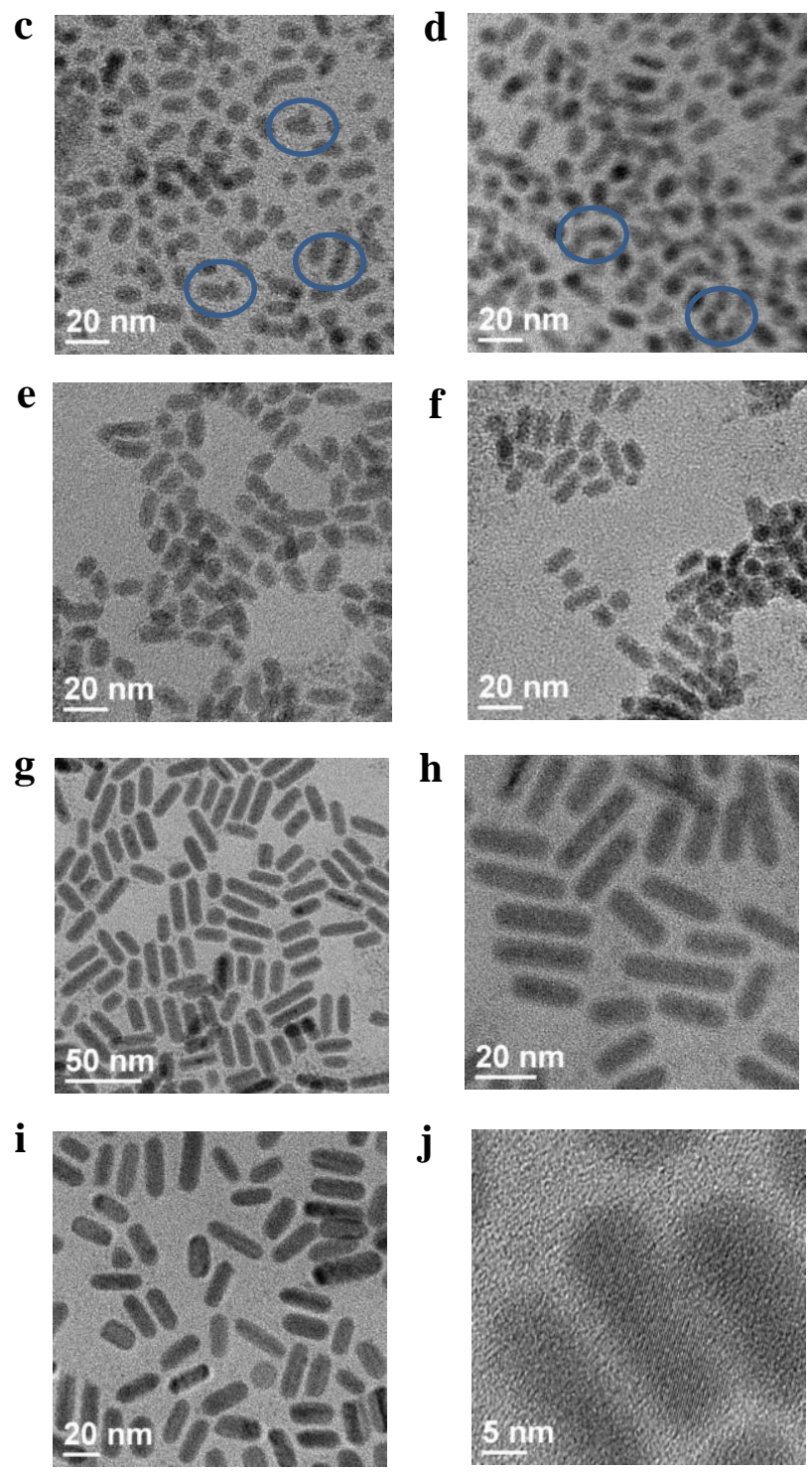

Figure S6 TEM images of SnTe nanorods prepared by heating the temperature to (a, b) $155{ }^{\circ} \mathrm{C},(\mathrm{c}, \mathrm{d}) 160{ }^{\circ} \mathrm{C}$, $(e, f) 165^{\circ} \mathrm{C},(\mathrm{g}, \mathrm{h}) 170{ }^{\circ} \mathrm{C}$ and $(\mathrm{i}, \mathrm{j}) 180^{\circ} \mathrm{C}$. Circled regions highlight evidence of dimer formation. 

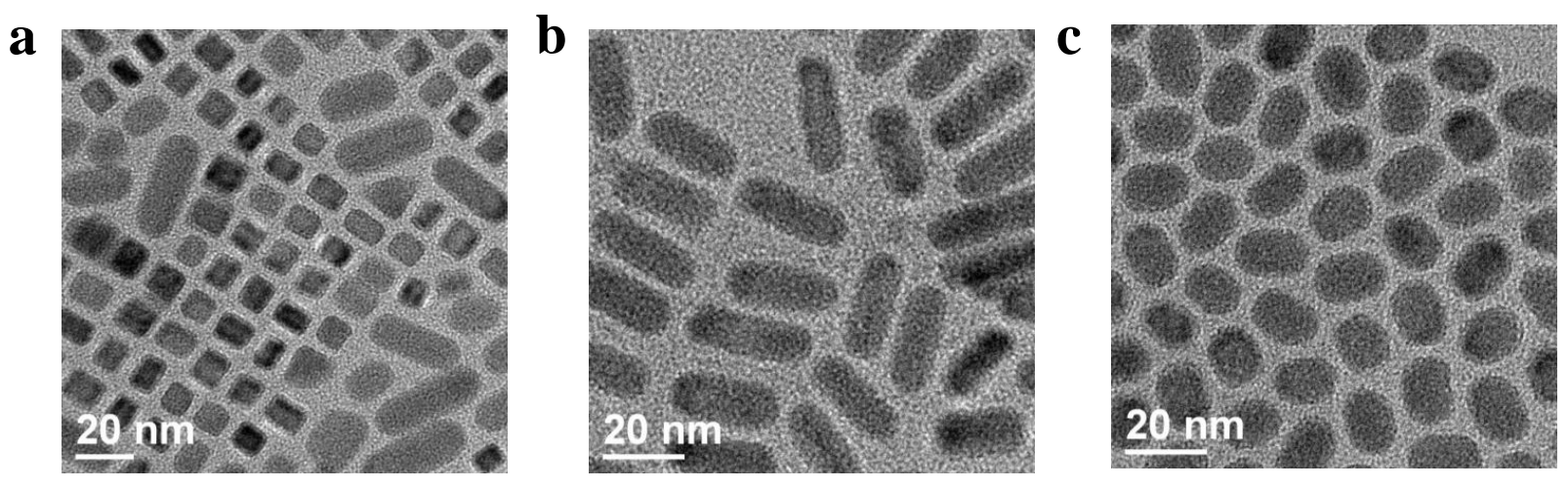

Figure S7 TEM images of SnTe nanocrystals prepared in the presence of (a) $0.0 \%$, (b) $0.1 \%$ and (c) $0.5 \%$ DIP.

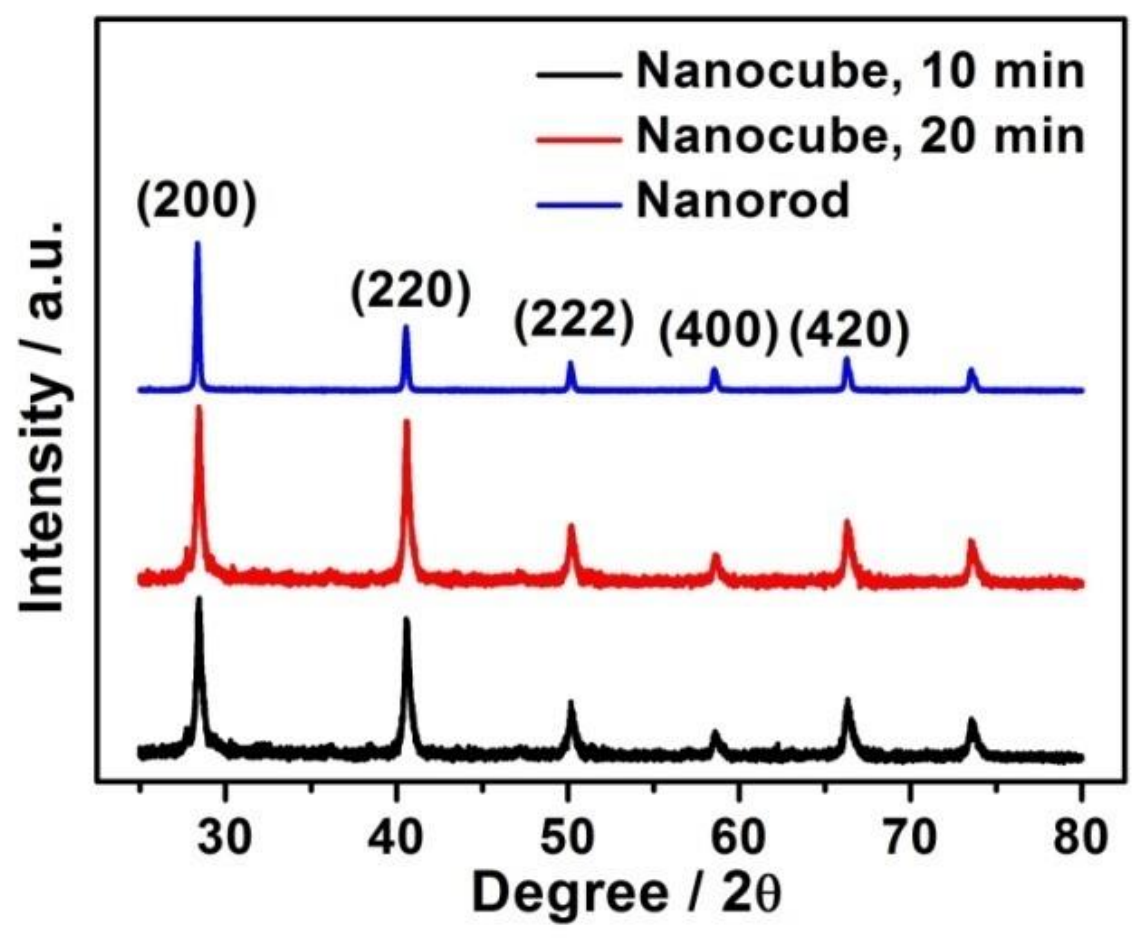

Figure S8. XRD patterns of nanocubes and nanorods. 
a

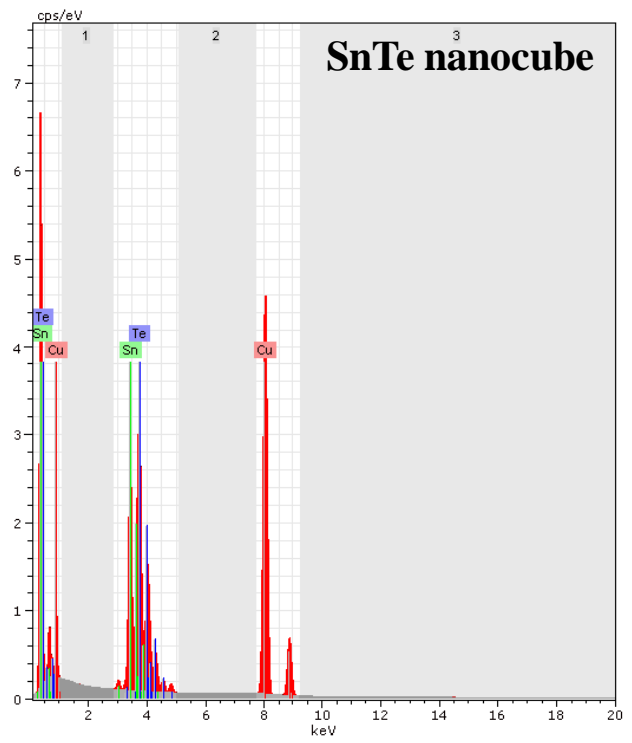

\begin{tabular}{rrrrrr} 
Element & series & [wt.\%] & $\begin{array}{r}\text { [norm. } \\
\text { wt.\%] }\end{array}$ & $\begin{array}{r}\text { [norm. } \\
\text { at.\%] }\end{array}$ & $\begin{array}{r}\text { Error in } \\
\%\end{array}$ \\
\hline Copper & K-series & 162.5856 & 27.31378 & 42.08492 & 4.114341 \\
Tin & L-series & 221.7531 & 37.25369 & 30.72663 & 15.82967 \\
Tellurium & L-series & 210.9126 & 35.43254 & 27.18845 & 9.904335 \\
& Sum: & 595.2513 & 100 & 100 &
\end{tabular}

b

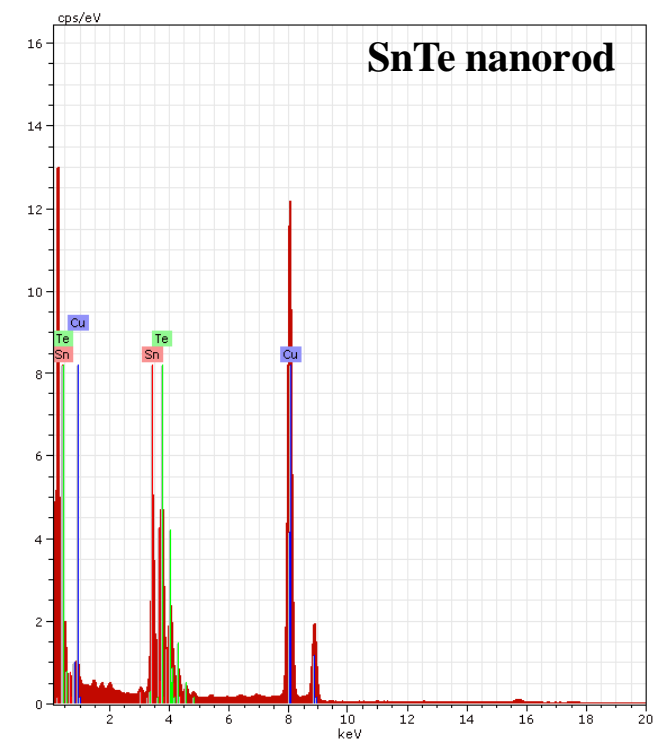

$\begin{array}{rrrrrr}\text { Element } & \text { series } & \text { [wt.\%] } & \begin{array}{r}\text { [norm. } \\ \text { wt.\%] }\end{array} & \begin{array}{r}\text { [norm. } \\ \text { at.\%] }\end{array} & \begin{array}{r}\text { Error in } \\ \%\end{array} \\ \text { Tin } & \text { L-series } & 169.5087 & 35.57951 & 28.13537 & 11.0945 \\ \text { Tellurium } & \text { L-series } & 149.6931 & 31.42025 & 23.11527 & 6.376409 \\ \text { Copper } & \text { K-series } & 157.2206 & 33.00025 & 48.74937 & 3.956723 \\ & \text { Sum: } & 476.4224 & 100 & 100 & \end{array}$

Figure S9 EDX elemental analysis data from SnTe (a) nanocubes and (b) nanorods. 


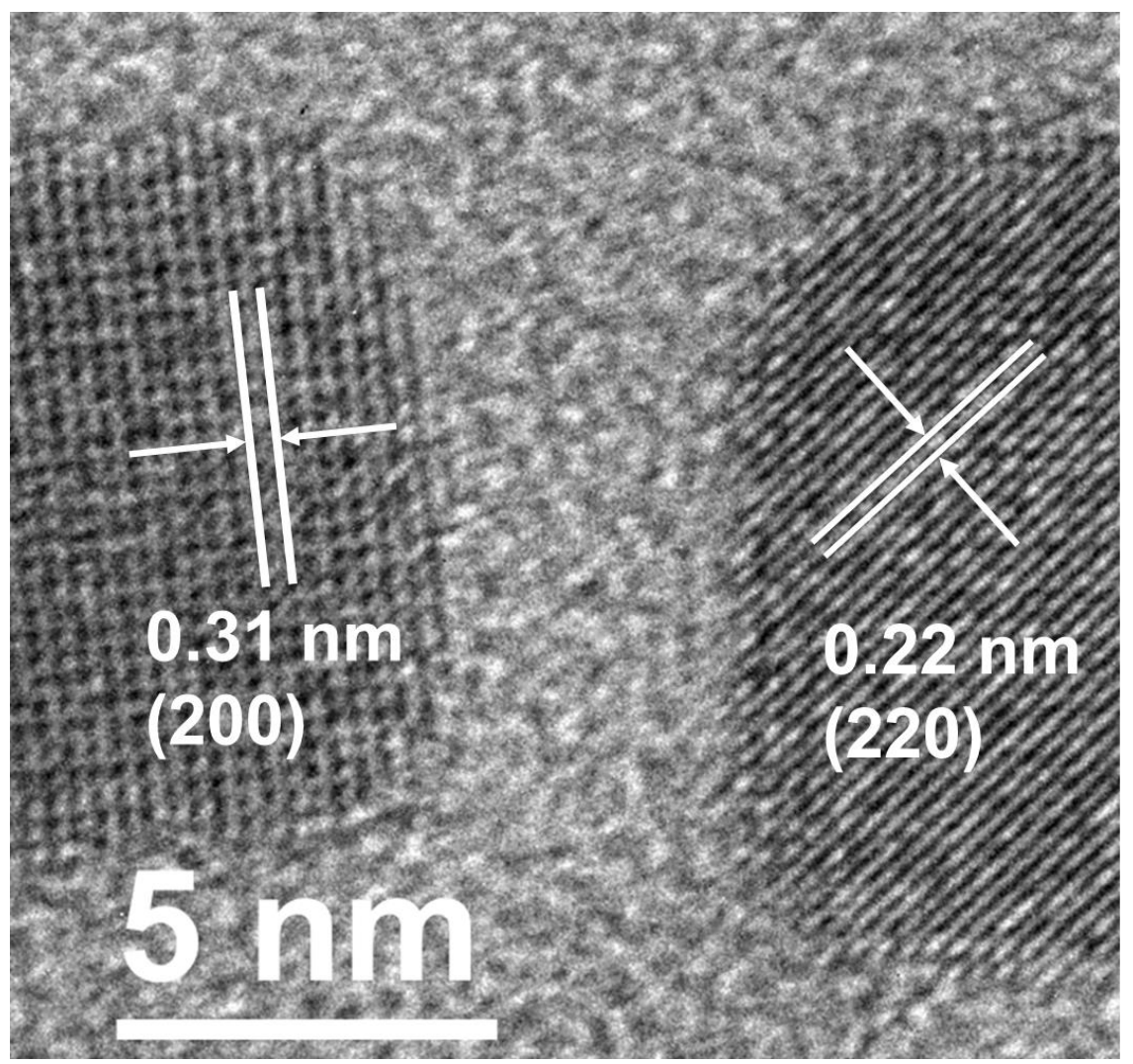

Figure S10. HRTEM of nanocubes, showing both (200) and (220) lattice fringes. The (200) fringes are always strictly parallel to nanocube sides, while the (220), when observed, are at an angle.

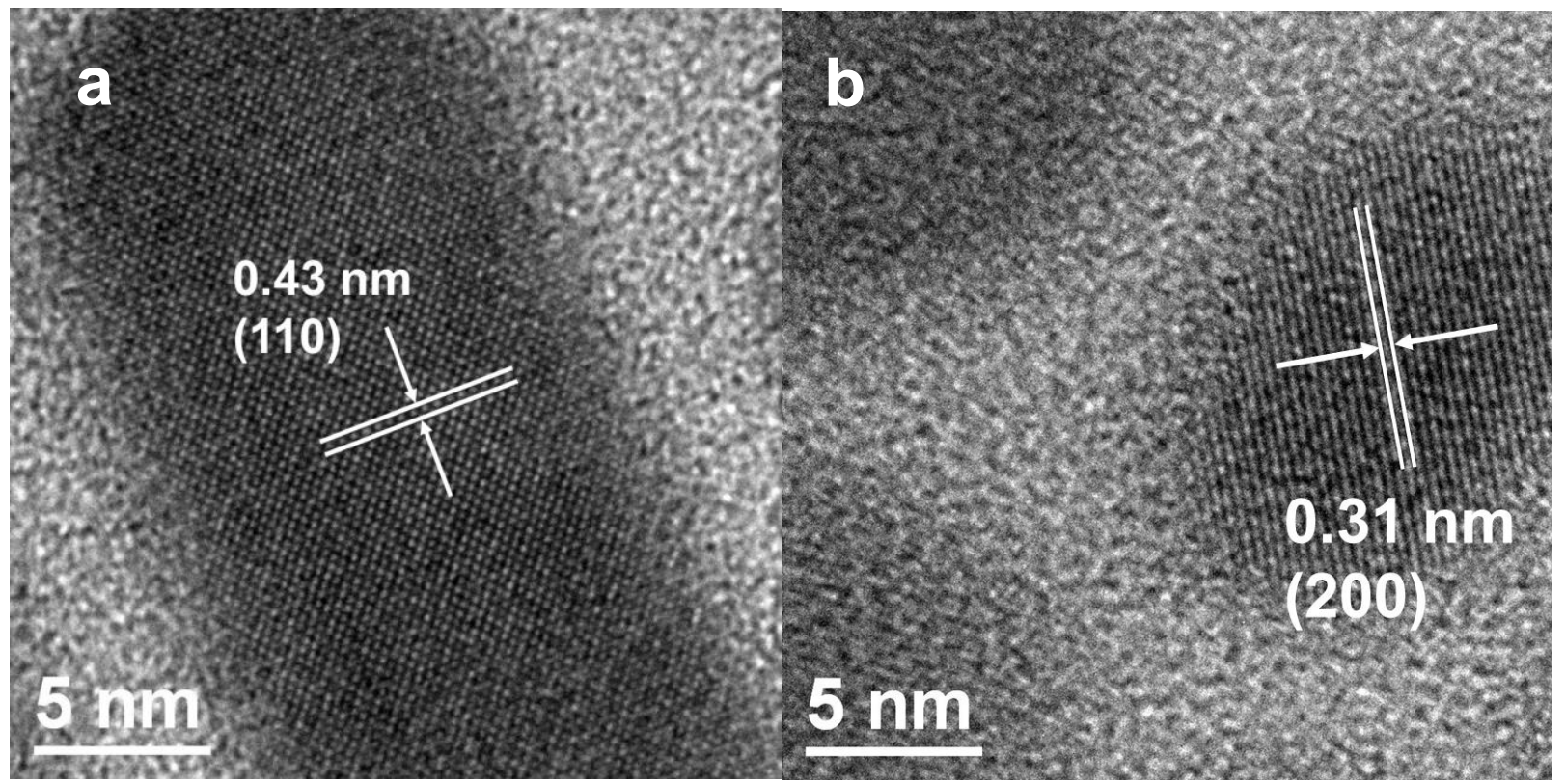

Figure S11. HRTEM of nanorods, showing both a) (110) and b) 200 lattice fringes. Both are consistent with elongation along the [220] direction. 
Table S1 Reaction parameters for the synthesis of SnTe nanocubes, nanorods and nanowires.

\begin{tabular}{|c|c|c|c|c|}
\hline Surfactant & $\begin{array}{c}\text { Injection } \\
\text { Temperature }\end{array}$ & $\begin{array}{c}\text { Reaction } \\
\text { Temperature }\end{array}$ & $\begin{array}{c}\text { Reaction } \\
\text { Time }\end{array}$ & $\begin{array}{c}\text { Morphology } \\
(d=\text { side length or diameter; } \rho=\text { aspect ratio })\end{array}$ \\
\hline TOP & $160{ }^{\circ} \mathrm{C}$ & $240{ }^{\circ} \mathrm{C}$ & $0-20 \mathrm{~min}$ & Nanocubes: $d=16 \pm 1.3 \mathrm{~nm}$ \\
\hline TOP+DIP & $40{ }^{\circ} \mathrm{C}$ & $180{ }^{\circ} \mathrm{C}$ & $0 \mathrm{~min}$ & Nanorods: $d=12.5 \pm 2 \mathrm{~nm} ; \rho \approx 1.4-1.8$ \\
\hline TOP+DIP & $40{ }^{\circ} \mathrm{C}$ & $180{ }^{\circ} \mathrm{C}$ & $10 \mathrm{~min}$ & Nanorods: $d=16 \pm 3 \mathrm{~nm} ; \rho \approx 2-2.5$ \\
\hline TOP+DIP & $40{ }^{\circ} \mathrm{C}$ & $180{ }^{\circ} \mathrm{C}$ & $30 \mathrm{~min}$ & Nanorods: $d=16 \pm 3 \mathrm{~nm} ; \rho \approx 2.7-3.5$ \\
\hline TOP+DIP & $40{ }^{\circ} \mathrm{C}$ & $180{ }^{\circ} \mathrm{C}$ & $1 \mathrm{~h}$ & Nanorods: $d=16 \pm 3 \mathrm{~nm} ; \rho \approx 4-7$ \\
\hline TOP+DIP & $40{ }^{\circ} \mathrm{C}$ & $180{ }^{\circ} \mathrm{C}$ & $4 \mathrm{~h}$ & Nanorods: $d=16 \pm 3 \mathrm{~nm} ; \rho \approx 7-20$ \\
\hline TOP+DIP & $40{ }^{\circ} \mathrm{C}$ & $180{ }^{\circ} \mathrm{C}$ & $8 \mathrm{~h}$ & Nanorods: $d=16 \pm 3 \mathrm{~nm} ; \rho>100$ \\
\hline TOP+DIP & $40{ }^{\circ} \mathrm{C}$ & $180{ }^{\circ} \mathrm{C}$ & $24 \mathrm{~h}$ & Nanorods: $d=16 \pm 3 \mathrm{~nm} ; \rho>100$ \\
\hline TOP+DIP & $90{ }^{\circ} \mathrm{C}$ & $180{ }^{\circ} \mathrm{C}$ & $3 \mathrm{~h}$ & Nanorods: $d=20 \pm 3 \mathrm{~nm} ; \rho \approx 3-7$ \\
\hline TOP+DIP & $120{ }^{\circ} \mathrm{C}$ & $180{ }^{\circ} \mathrm{C}$ & $4 \mathrm{~h}$ & Nanorods: $d=23 \pm 3 \mathrm{~nm} ; \rho \approx 7-17$ \\
\hline
\end{tabular}

